\title{
A ACCOUNTABILITY EM PARECERES PRÉVIOS DO TRIBUNAL DE CONTAS DO ESTADO DO PARANÁ: POSSÍVEIS CONSEQUÊNCIAS PARA O DESENVOLVIMENTO LOCAL
}

\author{
THE ACCOUNTABILITY IN PRIOR OPINIONS OF THE COURT OF \\ AUDITORS OF THE STATE OF PARANA: POSSIBLE \\ CONSEQUENCES FOR THE LOCAL DEVELOPMENT
}

\author{
Cristhian Carla Bueno de Albuquerque ${ }^{1}$ \\ Antônio Gonçalves de Oliveira ${ }^{2}$
}

\begin{abstract}
RESUMO
Este recorte demonstra os resultados da pesquisa que teve como objetivo verificar o potencial de accountability dos pareceres prévios produzidos pelo Tribunal de Contas do Estado do Paraná (TCE/PR) relativos às contas anuais dos prefeitos municipais no exercício financeiro de 2012, cujo objeto de análise encontra-se elencado em instruções normativas emitidas pelo próprio órgão, as quais definem o escopo de análise para cada exercício financeiro. Por intermédio dos estudos referenciados nas esferas exploratória, bibliográfica, documental e de observação teórico-empírica, observa-se que a Corte de Contas do Paraná, ao analisar a prestação de contas do governo municipal, não exerce todo o seu potencial de accountability, limitando-se aos aspectos da conformidade com a legalidade, não utilizando as possibilidades que a legislação the oferece, principalmente seu próprio Regimento Interno e, assim, deixa de contribuir para a materialização da accountability, eis que não adentra no aspecto substancial para atingir metas e executar políticas públicas e programas de governo, tarefa importantíssima para fins de dar à população dados efetivos e concretos sobre a gestão municipal e o desenvolvimento local, não apenas em seu aspecto econômico, mas também social e ambiental.
\end{abstract}

Palavras-chave: Accountability; Pareceres prévios; Tribunal de contas; Estado do Paraná, Desenvolvimento local.

\begin{abstract}
This clipping shows the research results that have as goal verify the potential of accountability of the prior opinions produced by the Court of Auditors of the State of Parana (TCE/PR) relative to the annual bills of the mayors in the financial exercise of 2012, which the analysis objects is found part listed in normative instructions issued by the organ itself, which define the analysis scope for each financial exercise. Through the studies referenced in the exploratory, bibliographic, documental and theoretical-empirical observation sphere, it is observed that the Court of Auditors of Parana, analyzed the municipal government accountability and don't exercises all your accountability potential, limiting to accordance with legality aspects, not using the possibilities that the legislation offers, specially your own Internal Rules and, this way, doesn't contribute for the accountability materialization that doesn't

\footnotetext{
${ }^{1}$ Graduada em Direito pela Universidade Estadual de Ponta Grossa (UEPG), servidora do Tribunal de Contas do Estado do Paraná, Advogada, mestranda em Governança e Planejamento Público na Universidade Tecnológica Federal do Paraná (UTFPR).

${ }^{2}$ Doutor em Engenharia de Produção pela Universidade Federal de Santa Catarina (UFSC), professor do Programa de Mestrado em Planejamento e Governança Pública (PPGPGP), da Universidade Tecnológica Federal do Paraná (UTFPR) e consultor CAPES/PNAP/PPA/Orçamento Público.
} 
enter in the substantial aspect of goals reaching and in the execution of public policies and programs of the government, important task to give effective and concrete data for the population about the municipal management and local development, not only in your economic aspect, but also social and environmental.

Keywords: Accountability; Prior opinions; Court of auditors; State of Paraná; Local development.

\section{Introdução}

A administração pública vem sendo estigmatizada pela escassez de recursos e por exigências cada vez maiores e mais criteriosas realizadas pela sociedade, que exige dos gestores públicos maior preocupação quanto à transparência administrativa e um controle mais eficiente no âmbito das instituições públicas (CALIXTO; VELÁZQUES, 2005).

Para o cumprimento dessas exigências, necessário se faz a existência de um sistema que comungue informações e organização institucional, com a finalidade de assegurar o cumprimento de políticas públicas, assegurando a consecução de boas práticas de gestão, para que a aplicação do dinheiro público seja eficaz, eficiente, econômica e legal.

Neste mister, a sociedade conta com órgãos de controle, a exemplo do Tribunal de Contas, que possuem autonomia e independência para a realização de suas atribuições, estas previstas em leis e regulamentos.

Um exemplo é o Tribunal de Contas do Estado do Paraná (TCE/PR), cujas competências estão previstas na Constituição Estadual em simetria com a Federal, em sua Lei Orgânica e no Regimento Interno, o qual possui o escopo de análise, controle e fiscalização do Estado e dos Municípios em relação aos aspectos orçamentários, patrimoniais, financeiros, legais e regulamentares.

Cabe ainda a esta Corte de Contas verificar o cumprimento e execução dos programas previstos no Plano Plurianual (PPA), Lei de Diretrizes Orçamentárias (LDO) e Lei Orçamentária Anual (LOA) quanto à consecução das metas e objetivos nelas previstos; além de avaliar o reflexo da execução financeiro-orçamentária no desenvolvimento econômico e social dos entes submetidos à sua jurisdição.

Nesse sentido, o cerne do problema que norteia este estudo funda-se no seguinte questionamento: os pareceres prévios são instrumentos de controle que possuem elevado potencial de accountability de forma a estimular boas práticas de gestão e o desenvolvimento local?

Guiado por este questionamento, o objetivo deste trabalho é realizar uma discussão, partindo de pesquisas exploratórias por meio da investigação bibliográfica e documental sobre o potencial de accountability dos pareceres prévios produzidos pelo Tribunal de Contas do Estado do Paraná e a sua influência no desenvolvimento dos Municípios fiscalizados.

Deste modo, o estudo na forma apresentada justifica-se teoricamente por se tratar de um tema emergente e pouco estudado, ao refletir sobre a eficácia dos pareceres prévios emitidos pela Corte de Contas do Estado do Paraná e suas possíveis consequências para o desenvolvimento local, haja vista a valorização dos princípios relacionados à governança, administração da (res)-pública e desenvolvimento local. Destaca-se que a accountability é uma ferramenta importante para a melhoria do desempenho estatal e fundamental para o aprimoramento e consolidação do Estado Democrático e de Direito, sendo assim indiscutível sua relevância para o aperfeiçoamento da Administração Pública.

Insta asseverar que o termo accountability não está incorporado ao dicionário brasileiro, sendo aqui utilizado como sinônimo de "prestação de contas", resguardadas as devidas proporções, quanto à sua amplitude e abrangência, que vai além de uma simples prestação de contas, pois, como argumentam Denhardt e Denhardt (2007), não se pode deixar 
de evidenciar a complexidade dos estudos sobre o tema, uma vez que as questões que envolvem a responsabilidade e a responsabilização no setor público são por natureza complexas.

Há ainda que se perquirir sobre o que corresponde exatamente a expressão "desenvolvimento local", quais suas implicações e extensão, eis que discussões sobre planejamento, gestão e sobre estratégias de desenvolvimento são temas em voga.

Quanto ao objetivo e justificativa deste trabalho, não há a pretensão de esgotar o assunto, que possui campo fértil para imersões futuras, pois, embora os resultados deste estudo não possam ir além do âmbito do TCE/PR, e tendo em vista que a accountability possui caráter progressivo, dependente de condições sociopolíticas, poderá ser aproveitado como referencial para pesquisas similares em outros TCs.

Dessa forma, respeitadas as limitações para atingir o objetivo proposto, norteado pela questão problema e pautado nos procedimentos metodológicos, este trabalho está dividido em seis partes/seções, somadas a esta introdução e às referências, que sustentam o embasamento teórico apresentado.

A primeira parte discorre sobre os principais aspectos do controle no âmbito da Administração Pública, dando enfoque aos tipos existentes e aos órgãos controladores.

Em seguida, a segunda parte versa sobre a accountability, seus aspectos conceituais e a atuação dos Tribunais de Contas, suas principais atribuições e aos limites do controle externo, em especial aquele exercido pelo Poder Legislativo com o auxílio dos Tribunais de Contas, com ênfase ao Tribunal de Contas do Estado do Paraná, do qual foram extraídos os dados e as informações que serviram de base para satisfizer às inquietações suscitadas neste recorte.

A terceira parte trata da conceituação de parecer prévio e das normativas do Tribunal de Contas do Estado do Paraná, que subsidiam a análise das prestações de contas dos prefeitos municipais no exercício de 2012. Na sequência, faz-se um questionamento sobre as possíveis consequências da análise das contas municipais pela Corte de Contas para o desenvolvimento local, de forma a conceituar o termo.

Os procedimentos metodológicos estão descritos na quinta parte deste estudo, por meio dos quais se efetivou a pesquisa, reconhecendo-se as possíveis limitações dos métodos utilizados, dado o entendimento de que eles não são finitos e imutáveis, sendo sempre passíveis de questionamentos e melhorias constantes.

Finalizando, a sexta parte faz menção às considerações finais, demonstrando de forma sintética e objetiva os resultados obtidos com o presente estudo.

\section{Controle na Administração Pública}

No Estado Democrático de Direito, o agir do gestor público é balizado pelo conjunto de normas editadas pelo Poder Legislativo, sendo seu dever agir de acordo com estas normas, obedecendo e observando as leis e os princípios vigentes no país (GARCIA; ALVES, 2002, p. 19-20).

Desta feita, a essência dessa forma de Estado se revela na conjunção simultânea dos ditames da juridicidade, legalidade, interesse público, dignidade da pessoa humana, ou seja, objetiva a garantia das liberdades civis.

Para assegurar esses preceitos, é necessário que haja o controle dos atos de gestão do administrador público, visando à garantia das boas práticas de governança pública.

Como argumenta Matias-Pereira (2010, p. 167), “o controle é uma atividade inerente a qualquer tipo de instituição ou organização, compreendendo, além dos aspectos administrativos e financeiros, todo o conjunto de métodos e ações realizados dentro de 
determinado órgão administrativo".

Deste modo, por intermédio de efetivas técnicas de controle garante-se não apenas o cumprimento das normas, mas também que sejam atingidas as metas essenciais do ente público, ou seja, o desenvolvimento e a execução eficientes de políticas públicas que integram a agenda governamental, assegurando a continuidade do Estado em direção ao bem comum, nos moldes apregoados por Justen Filho (2011, p. 1100), que afirma ser "o Estado uma organização de bens e pessoas para a realização dos direitos fundamentais."

Assim, denota-se que a finalidade do sistema de controle da gestão pública é assegurar que o administrador atue em consonância com os princípios da legalidade, moralidade, finalidade pública, publicidade, motivação e impessoalidade (DI PIETRO, 2011, p. 735), podendo somar-se a estes a observância dos princípios da indisponibilidade e supremacia do interesse público.

$\mathrm{Na}$ administração pública, considerando o espectro de abrangência nas três esferas do federalismo brasileiro, bem como a necessidade de consolidação de instrumentos de gestão para subsídio às decisões e à efetivação das políticas públicas, a implementação do controle se dá de forma sistêmica nos âmbitos interno e externo, sendo que os sistemas que dão o devido suporte devem ser acionados para estabelecer mecanismos que, aderentes à "filosofia" de gestão pautada nos princípios de governança pública, assegurem a lisura e transparência nos atos dos gestores públicos.

Neste matiz, infere-se que o controle externo "é o dever-poder atribuído constitucionalmente e instituído por lei como competência específica de certos poderes e órgãos" (JUSTEN FILHO, 2011, p. 1111), sendo ele exercido pelo Poder Legislativo com auxílio dos Tribunais de Contas; pelo Poder Judiciário e também pela sociedade, que participa diretamente dele quando o provoca para defesa de interesses individuais e/ou coletivos, sendo este controle, inclusive, imprescindível para a concretização do Estado Democrático.

Sem adentrar no mérito de todas as formas de controle externo, o presente estudo limita sua abrangência ao controle exercido pelo Poder Legislativo, que nas palavras de Matias-Pereira (2010, p. 173), aderente à Di Pietro (2011), é aquele realizado pelas Casas Parlamentares: Senado e Câmara dos Deputados; Assembleias Legislativas; e Câmaras de Vereadores, efetivando-se internamente nessas casas por meio de comissões parlamentares de inquérito, convocação de autoridades, pedidos escritos de informação, fiscalização contábil, financeira e orçamentária, sustação dos atos normativos do executivo.

Este controle exercido pelo Poder Legislativo, dada a sua gama de atribuições, por força de previsão constitucional, ${ }^{3}$ pode ser realizado com o auxílio do Tribunal de Contas, órgão autônomo que fiscaliza os gastos do Poder Executivo, nos termos e competências fixadas taxativamente pelo diploma Constitucional, o qual é objeto específico de estudo deste recorte.

Cabe, desta feita, investigar a afetividade do exercício deste controle, principalmente no que tange ao escopo de análise para emissão dos pareceres prévios nas contas anuais dos gestores municipais, dada a implicação desta ao desenvolvimento local.

\section{A accountability e a atuação dos Tribunais de Contas}

Como descrito no tópico anterior, indiscutível a importância dos órgãos de controle e do próprio controle dos atos de gestão pública, visando a maior efetividade e economicidade

\footnotetext{
${ }^{3}$ Art. 71 da CF/88 - O controle externo, a cargo do Congresso Nacional, será exercido com o auxílio do Tribunal de Contas da União, ao qual compete [...].
} 
dos gastos públicos e à garantia de execução de políticas e dos programas que fazem parte da agenda governamental.

Para que este controle ocorra de forma eficaz, necessário se faz que os gestores se submetam à accountability.

Afinal, qual a amplitude e significado do termo "accountability"? Campos (1990, p. 47) menciona em seu trabalho que estudar accountability é uma tentativa de reduzir o hiato existente entre a efetividade das ações governamentais e as necessidades dos cidadãos. Para a autora, "o grau de accountability de uma determinada burocracia é explicado pela textura política e institucional da sociedade; os valores e os costumes tradicionais partilhados na cultura; pela história", indo muito além de uma simples análise de aspectos financeiros e orçamentários.

Pinho e Sacramento (2009, p. 1364), aperfeiçoando as tratativas dadas ao tema por Campos (1990), constatam que o significado do conceito "envolve responsabilidade (objetiva e subjetiva), controle, transparência, obrigação de prestação de contas, justificativas para as ações que foram ou deixaram de ser empreendidas, premiação e/ou castigo."

Como sintetiza Rocha (2013, p. 904) "a accountability pode ser interpretada como um processo de avaliação e responsabilização permanente dos agentes públicos pelo uso do poder que lhes é concedido pela sociedade, desde que esta responsabilização se dê mediante algum tipo de sanção, seja negativa (punição) ou positiva (prêmio), e tenha ela natureza legal ou moral".

Assim, a accountability se revela um instrumento imprescindível de gestão pública, uma vez que se traduz em "meios democráticos de monitorar e controlar a conduta dos governantes, por prevenir concentrações de poder e por aumentar a capacidade de aprendizado e a efetividade da administração pública" (BOVENS, 2006, p. 25).

Talvez em decorrência dessa abrangência o poder constituinte tenha previsto o dever dos gestores públicos de realizarem suas prestações de contas e tenha ampliado as atribuições, poderes e a autonomia dos Tribunais de Contas, órgãos estes participantes no processo, nos termos do Art. 71 da CF/88, já referenciado.

Chaves (2009, p. 94) define tribunal de contas como um "órgão de extração constitucional, autônomo e independente - cuja previsão de existência e competências básicas constam da própria Lei Magna”.

Estes tribunais receberam a partir da carta constitucional aparato legal que lhes permite vastas condições de promover a accountability, os quais devem expandir sua atuação de forma a não se limitar apenas à análise dos aspectos contábeis e orçamentários, pois, como assevera Campos (1990, p. 45), "além da questão da autonomia, a própria natureza do controle constitui uma limitação: enquanto a Corte se limitar a aspectos contábeis e orçamentários, a burocracia não se moverá no sentido da accountability".

Evidenciando-se a evolução desses Tribunais ao longo dos tempos, as atividades de controle passaram a englobar amplas atividades, com vários objetivos, sendo seu papel tradicional o de assegurar que os recursos públicos sejam arrecadados e aplicados de acordo com as leis e regulamentos existentes, evoluindo atualmente para o controle dos resultados, e não apenas da legalidade, como eram em seus primórdios (GIACOMONI, 2010, p. 337).

Ainda, Giacomoni (2010, p. 337) enfatiza que os Tribunais de Contas: 
[...] cumprem uma ampla gama de atividades com objetivos distintos. Tradicionalmente tem sido um mecanismo tendente a assegurar, ao governo e aos seus ministérios (controle interno) e ao Poder Legislativo (controle externo), que os recursos públicos sejam arrecadados e aplicados de acordo com as dotações orçamentárias e outras leis relevantes (controle de conformidade) e que o uso dado aos recursos de acordo com a administração representa total e exatamente a sua posição financeira (controle financeiro). A função de controle foi evoluindo em muitos países até adquirir uma visão mais completa das consequências econômicas e sociais das operações governamentais - aquilo que geralmente se denomina 'valor por dinheiro' ou controle de resultados.

No Brasil, existem 34 Cortes de Contas, das quais uma é da União, 27 Estaduais, 2 Municipais e 4 de Municípios, integradas por ministros ou conselheiros, cujas decisões em sua maioria são coletivas.

É fato que estas Cortes de Contas, como descrito alhures, exercem funções imprescindíveis de fiscalização, controle e orientação, e para esse mister utilizam-se não apenas da Constituição Federal, mas de todo um aparato legal e normativo existente em matéria de gastos públicos, contabilidade e controle, em especial a Lei de Responsabilidade Fiscal (LRF), a Lei de Contabilidade Pública, seus Regimentos Internos e Leis Orgânicas. Assim, as "questões centrais de interesse do controle externo são os aspectos legais ligados à arrecadação e aplicação do dinheiro público e à observância dos limites financeiros consignados no orçamento" (GIACOMONI, 2010, p. 340).

Como delimitação da esfera de análise do presente recorte, é dada ênfase aos aspectos de atuação do Tribunal de Contas do Estado do Paraná (TCE-PR), que teve sua origem seminal em 2 de junho de 1947. Justifica tal limitação em razão de dois motivos: I) por ter, na visão dos autores, apresentado evolução expressiva dentre os demais Tribunais de Contas existentes no país; II) pela facilidade de coleta de dados e informações, uma vez que estão todos informatizados (processos eletrônicos), bem como pela ligação direta de um dos autores com o órgão.

No site institucional do órgão, é possível observar que esta Corte de Contas Estadual, nos moldes das demais, teve em seus primórdios apenas a preocupação única de atuar como órgão de fiscalização, cuja visão veio evoluindo paulatinamente, de forma a aprimorar suas técnicas fiscalizatórias, englobando inclusive mais entidades e órgãos a serem controlados. Apenas na década de 80 exerceu o importante papel de orientação mediante treinamentos disponibilizados para os entes Municipais (Prefeituras e Câmaras). ${ }^{4}$

Nesta mesma década, mais precisamente após o advento da Carta Constitucional de 1988, o Tribunal de Contas do Estado do Paraná regulamentou a participação da população em atos de controle, normatizando o direito de denúncia. Fato este que, somado ao aparato eletrônico desenvolvido, propiciou à esta Corte de Contas ganhar a credibilidade da população e o título, em âmbito nacional, de Tribunal de Contas pioneiro no processo eletrônico e na preocupação de normatização para fins de possibilitar o exercício do controle social (PARANÁ, 2013).

Em que pese a evolução tida por esta Corte de Contas do Estado Paraná, deve-se perquirir sobre sua atuação quando da emissão dos pareceres prévios, se atendem aos anseios sociais, afinal, em estudo realizado, no qual tinham por escopo avaliar a imagem dos tribunais de contas subnacionais, Arantes, Abrucio e Teixeira (2005) concluíram que essas Cortes

\footnotetext{
4 <www.tce.pr.gov.br/historico>.
} 
possuem uma avaliação positiva, embora a sociedade deseje que suas decisões e seus atos de controle alcancem a efetividade das políticas governamentais, aproximando-se da substância da accountability.

E é esta inquietação que norteará este estudo nas próximas seções, a fim de verificar a forma de atuação do Tribunal de Contas do Estado do Paraná quando da emissão de pareceres prévios às contas dos prefeitos municipais, para fins de verificar o potencial de accountability existente nessas análises e possíveis consequências para o desenvolvimento local.

\section{Pareceres prévios emitidos pelo Tribunal de Contas no Estado do Paraná e o escopo da análise das prestações de contas anuais dos prefeitos}

Parecer prévio "é uma peça técnica, instrumento de apreciação das contas que dará suporte para o julgamento delas pelo Poder Legislativo" (GUERRA, 2005, p. 172).

Verifica-se que esta definição de parecer prévio por Guerra (2005) nada mais é que uma síntese do que dispõe a legislação nacional sobre a matéria, pois o Art. 71, inciso I, da $\mathrm{CF} / 88$ prevê que o controle externo realizado pelo Congresso Nacional será exercido com o auxílio do Tribunal de Contas da União, ao qual compete a apreciação das contas anuais prestadas pelo Presidente da República, mediante parecer prévio (BRASIL, 1988).

No mesmo sentido, a Lei de Responsabilidade Fiscal, em seu Art. 56, dispõe que as contas prestadas pelo chefe do Poder Executivo receberão parecer prévio da respectiva Corte de Contas, acrescentando em seu Art. 58 que nela deverá conter as questões atinentes à arrecadação, sua previsão, as providências adotadas no âmbito da fiscalização das receitas e combate à sonegação, as ações de recuperação de créditos e demais medidas para incremento das receitas tributárias e de contribuições (BRASIL, 2000).

Alicerçado nos dispositivos legais citados, e na Constituição Estadual, o Tribunal de Contas do Estado do Paraná, da mesma forma, elenca em sua Lei Orgânica, Lei Complementar $n^{\circ} 113 / 2005$, como primeira atribuição apreciar as contas prestadas anualmente pelos chefes dos poderes executivos, ${ }^{5}$ regulamentando o dispositivo na seção II de seu Regimento Interno, que trata "Das Contas dos Prefeitos Municipais" (PARANÁ, 2005).

Nesta seção II resta definida (arts. 215 e 216) a abrangência da matéria analisada na prestação de contas anual, a qual inclui a gestão orçamentária, contábil, financeira, patrimonial e operacional, bem como a atuação do controle interno. Essa mesma seção autoriza, ainda, que a forma da prestação de contas, sua composição e a instituição da agenda de obrigações municipais, que consolida prazos e compromissos, serão realizadas através de Instrução Normativa (IN) (PARANÁ, 2006).

Diante desse permissivo, o Tribunal de Contas do Estado do Paraná define o escopo de análise da prestação de contas de cada exercício financeiro do Poder Executivo mediante edição de Instrução Normativa.

A exemplo da prestação de contas relativas ao exercício de 2012, última prestação de contas analisada, a Instrução editada foi a IN 65/2011 (PARANÁ, 2011), a qual é objeto de análise deste trabalho para fins de se verificar o potencial de accountability dos pareceres prévios emitidos pela Corte de Contas do Estado do Paraná, cujo escopo de análise restou

\footnotetext{
5 Art. $1^{\circ}$. Ao Tribunal de Contas do Estado, órgão constitucional de controle externo, com sede na Capital do Estado, compete, nos termos da Constituição Estadual e na forma estabelecida nesta lei:

I - apreciar as contas prestadas anualmente pelo Governador do Estado e pelos Prefeitos Municipais, mediante parecer prévio, que deverá ser elaborado nos prazos gerais previstos na Constituição Estadual, na Lei de Responsabilidade Fiscal, e nos prazos específicos previstos nesta lei.
} 
disciplinada pela IN 90/2013 (PARANÁ, 2013).

O anexo 3 da Instrução Normativa n. 65/2011 elenca os documentos a serem enviados pelo Poder Executivo dos Municípios do Estado do Paraná para fins de análise da prestação de contas anual.

Observa-se da leitura do documento que a preocupação da Corte de Contas Estadual se limita aos aspectos formais, conformidade com as normativas da Corte de Contas, e encaminhamento de documentos que demonstrem a conformidade orçamentária, contábil, financeira e o cumprimento das exigências da Lei de Responsabilidade Fiscal, elencados em itens da seguinte forma: a) ofício de encaminhamento da prestação de contas; b) formulário de dados de prestação de contas municipal; c) índice com denominação de paginação dos documentos; d) certificação do contador; e) cópias dos extratos bancários; f) documento emitido pelos bancos com descrição das contas da entidade, saldo e tipo de conta; g) extratos bancários de janeiro do exercício seguinte ao da prestação de contas em que ocorram as conciliações bancárias e regularização de valores; h) declaração de inexistência de agência de banco oficial no Município; i) razão contábil, na qual constem os lançamentos das regularizações dos valores conciliados; j) certificado de regularidade previdenciária; k) certificado de regularidade dos recolhimentos INSS e FGTS; 1) peças contábeis e demonstrativos contábeis: Balanço Orçamentário, Financeiro e patrimonial, Demonstração das Variações Patrimoniais, Demonstração da Dívida Fundada, Demonstração da Dívida Flutuante, Publicação das Demonstrações Contábeis no Diário Oficial do Município e/ou em outro jornal de circulação; m) relatório e parecer do controle interno; n) atos de remuneração dos agentes políticos; o) resolução do conselho de saúde; p) parecer do conselho municipal de saúde; e, q) laudo atuarial com vigência aplicável ao exercício (PARANÁ, 2011).

Denota-se que não há exigência do encaminhamento pelos Municípios do plano plurianual (PPA), o qual estabelece as diretrizes, objetivos e metas do Governo ao longo de quatro anos, ou seja, instrumento primordial para análise da efetividade das políticas e programas de governo (CF/88, art. 165).

A normativa citada alhures define igualmente o modelo do relatório a ser encaminhado pelo órgão de controle interno municipal, e o item 5 desse documento dispõe sobre a síntese das avaliações:

Quadro 1 - Síntese das Avaliações Controle Interno - IN 65/2011

\begin{tabular}{|c|l|}
\hline \multicolumn{1}{|c|}{ Procedimentos realizados (*) } & Avaliação (**) \\
\hline Planos e Políticas de Governo & \\
\hline Cumprimento das Metas contidas no Plano Plurianual & $* *$ \\
\hline Eficácia da aplicação das políticas de governo & $* *$ \\
\hline Estimativas da receita em bases conservadoras & $* *$ \\
\hline Adequação da LOA ao PPA e à LDO & \\
\hline Diretrizes contidas na LDO & $* *$ \\
\hline Ações e programas do PPA previstos para o período & $* *$ \\
\hline
\end{tabular}

Fonte: Paraná (2011).

Conforme se vislumbra no Quadro 1, o Tribunal de Contas do Estado do Paraná deixa a cargo exclusivamente do controle interno de cada Município a avaliação da efetividade dos planos, programas e políticas de Governo, confiando fidedignamente nos dados avaliados pelo órgão, cujo responsável (controlador) é nomeado pelo próprio Chefe do Poder Executivo.

Essa conclusão é extraída do anexo I da Instrução Normativa n. 90/2013, que define o escopo de análise das contas anuais do exercício de 2012 (PARANÁ, 2013), a qual prevê como forma de restrição às contas anuais os seguintes aspectos: falta de encaminhamento do 
relatório do controle interno e relatório do controle interno encaminhado não satisfaz os conteúdos mínimos prescritos pelo tribunal.

O escopo de análise do Tribunal de Contas do Paraná restringe-se apenas às formalidades do relatório encaminhado pelo controle interno, ou seja, se o relatório foi efetivamente encaminhado, e se foi preenchido com os conteúdos mínimos exigidos, aspectos meramente formais, sem adentrar na avaliação do mérito do documento.

Há sequer avaliação dos critérios e indicadores utilizados pelo órgão de controle interno quando atesta o cumprimento e/ou descumprimento das metas governamentais, quando analisa a efetividade, economicidade, eficiência da gestão na execução de seus planos, programas e políticas.

Como salienta Lins (2012, p. 74), "o Tribunal de Contas é o único órgão autorizado a fiscalizar as contas do Município e emitir parecer prévio sobre a gestão do administrador público", e como se constata das IN 65/2011 e 90/2013, o Tribunal de Contas do Estado do Paraná aprecia os aspectos orçamentários, financeiros, fiscais (LC 101/2000), contábeis, patrimoniais e legais para emissão de seus pareceres prévios, deixando a cargo exclusivamente do controle interno a efetividade das políticas públicas.

No entanto, o Regimento Interno do Órgão prevê em sua seção II (arts. 215 e 216) que a análise das prestações de contas anuais deve incluir a gestão operacional, descumprindo, assim, o princípio da legalidade, uma vez que não se vislumbra das normativas emitidas pela Corte de Contas ponderações a respeito do aspecto de efetividade, implementação e execução dos programas governamentais e das ações de governos, quanto ao seu desempenho, atuação ética, observância dos princípios democráticos e a satisfação do interesse público (gestão operacional).

Ademais, como cita Castro (2003, p. 26).

O Supremo Tribunal Federal mantém o entendimento, quanto à forma de apreciação e seus aspectos, de que: "A apreciação das contas anuais da chefia do executivo constitui uma das mais elevadas atribuições do Tribunal de Contas, a quem compete examiná-las de forma global, mediante parecer prévio, no que concerne aos seus aspectos de legalidade, legitimidade e economicidade." Destaca, ainda, que o parecer prévio se trata de “... pronunciamento técnico, sem conteúdo deliberativo, consubstanciado em parecer prévio, destinado a subsidiar o exercício das atribuições fiscalizadoras do Poder Legislativo".

Pautados nas definições de Campos (1990, p. 47) e de Pinho e Sacramento (2009, p. 1364) sobre accountability, e considerando seu aspecto substancial de reduzir o hiato existente entre a efetividade das ações governamentais e as necessidades dos cidadãos, constata-se que o Tribunal de Contas do Estado do Paraná, ao apreciar as contas anuais dos Prefeitos Municipais relativas ao exercício de 2012, não exerce todo o seu potencial de accountability.

Diante dessa constatação, cumpre-se verificar quais as possíveis consequências geradas pela falta de controle sobre a implementação e execução dos planos e políticas do Governo Municipal, pelo Tribunal de Contas, para o desenvolvimento local, eis que o parecer prévio emitido por essa Corte de Contas é o pronunciamento técnico, destinado a subsidiar o julgamento das contas pelo Poder Legislativo. 


\section{Possíveis consequências ao desenvolvimento local}

A avaliação das políticas públicas e das ações governamentais "assume a função de legitimação" (TREVISAN; VAN BELLEN, 2008, p. 548), configurando-se em um verdadeiro instrumento democrático, pois por meio dela a população terá pleno acesso às informações, metodologia empregada e aos resultados obtidos, podendo mensurar as consequências e a sustentabilidade do desenvolvimento.

Afinal, como argumentam Silva e Bassi (2012, p. 37), “espera-se que uma política pública seja efetiva ao definir e alcançar seus objetivos (eficácia) e com a menor utilização de recursos (eficiência)".

Corroborando, Ala-Harja e Helgason (2000, p. 8) afirmam que "o termo compreende a avaliação dos resultados de um programa em relação aos objetivos propostos”.

Assim, se mostra imprescindível o papel do Tribunal de Contas Estadual nesse mister como órgão de controle externo, uma vez que a sua atuação acarretará maior comprometimento e responsabilidade dos gestores municipais na implementação de suas políticas públicas, proporcionando maior transparência, um retorno efetivo à população local, indo ao encontro dos anseios da sociedade e, consequentemente, se aproximando da accountability, pois, como preceitua Justen Filho (2006, p. 748), "a submissão da atuação de um sujeito à fiscalização alheia produz efeito de orientação de sua conduta. Aquele que sabe que seus atos serão objeto de fiscalização orienta a própria conduta para evitar reprovações".

Conceituando-se o desenvolvimento não apenas como sinônimo de desenvolvimento econômico, mas como uma mudança social positiva, de forma a aumentar a qualidade de vida da população, proporcionar a justiça social e modificar o local onde essas relações ocorrem (SOUZA, 2002, p. 60), evidencia-se que a falta de avaliação das políticas governamentais em seus três eixos, de efetividade, eficácia e eficiência, pode acarretar consequências gravosas em face da não satisfação das necessidades básicas de uma parcela cada vez maior da população.

Além disso, essa ausência de avaliação (controle) pela Corte de Contas Estadual compromete tanto o sistema democrático representativo - uma vez que a escolha do gestor ocorre, em tese, a partir de suas proposições políticas - como o planejamento da gestão, eis que "planejar significa tentar prever a evolução de um fenômeno (...) tentar simular os desdobramentos de um processo, com o objetivo de melhor precaver-se contra prováveis problemas ou (...) melhor tirar partido de prováveis benefícios" (SOUZA, 2002, p. 46), assim, se não há a avaliação dos programas e políticas no presente não se pode aferir a sua conformidade com os instrumentos de planejamento público (PPA, LDO, LOA), nem mesmo sua efetividade futura.

Ao final, verifica-se que tal prática fere o princípio da transparência, tão em voga nos dias atuais, eis que empiricamente se constata que os gestores públicos prestam contas apenas em relação ao que são obrigados em função de dispositivo legal ou ato normativo, não estando ainda inserido em sua cultura como algo espontâneo, assim, se não há exigência do órgão de controle externo, não há interesse imediato pelo administrador público.

É importante frisar que esse controle da execução de políticas públicas é uma garantia da sociedade, como direito fundamental de obter explicações sobre os atos e ações de seus representantes, e uma forma de possibilitar escolhas melhores no momento do pleito eleitoral.

\section{Metodologia}

O método de pesquisa utilizado neste recorte, em consonância com a taxionomia empregada por Vergara (2004, p. 46-50), fundamenta-se em dois critérios: quanto aos fins e quanto aos meios. Quanto aos fins, caracteriza-se em pesquisa exploratória e explicativa; ressaltando-se, conforme destaque dado pela autora, que uma investigação exploratória não 
deve ser confundida com uma simples leitura exploratória, uma vez que aquela é realizada em pesquisas envolvendo áreas de evolução constante, quanto às modificações e evoluções da sociedade (com pouco conhecimento acumulado), e que, por sua natureza de sondagem, não comporta hipóteses que, todavia, poderão surgir durante ou no fim da pesquisa, razão pela qual se tem, neste estudo, a proposição de sugestão para novos estudos.

A investigação explicativa, segundo Vergara (2004, p. 47), tem como principal objetivo "tornar algo inteligível justificando-lhe os motivos. Visa, portanto, esclarecer quais fatores contribui de alguma forma para a ocorrência de determinado fenômeno". Por esse motivo, o estudo aqui desenvolvido trata do imbricamento, da interdependência e da importância da accountability, do controle externo exercido pelo Tribunal de Contas e as consequências para o desenvolvimento local.

Quanto aos meios de investigação, foram utilizados neste estudo a investigação bibliográfica e documental, devendo-se registrar que a de cunho bibliográfico (VERGARA, 2004, p. 48) "é representada pelo estudo sistematizado desenvolvido com base no material publicado em livros, revistas, jornais, redes eletrônicas, isto é, acessível ao público em geral" (relevante instrumento analítico para qualquer outro tipo de pesquisa). Este recorte utilizou de pesquisa bibliográfica aderente ao tema em estudo (controle exercido pelos Tribunais de Contas quando analisa as contas anuais do executivo municipal), em livros, revistas, artigos científicos relevantes publicados em revistas científicas impressas e/ou eletrônicas, e matérias disponibilizadas na internet.

Nesse mesmo matiz, é também empregada a pesquisa de cunho documental e de observação teórico-empírica (VERGARA, 2004, p. 48). Documental porque se fundamenta em levantamentos extraídos de documentos regulatórios oficiais publicados: Leis, Decretos, Portarias, Resoluções, Instruções, material extraído do Tribunal de Contas do Estado do Paraná, etc.; e de observação teórico-empírica, em virtude da condução pelos autores no dia a dia das suas vivências acadêmico-profissionais no âmbito do Grupo de Pesquisa que é a fonte seminal da inquietude originária do desenvolvimento deste recorte, em especial na observação semanal das sessões de julgamentos realizadas na Corte de Contas do Estado do Paraná, no período de março a dezembro de 2013.

Considerando a contribuição de Oliveira, Carvalho e Corrêa (2013), destaque-se que ensaios de caráter exploratório realizados pelos meios bibliográfico, documental e de observação, como o consubstanciado neste estudo, vem sendo amplamente valorizados e aceitos no mundo acadêmico, considerando a abrangência, relevância e as contribuições do assunto estudado.

Sabe-se que na academia é valorizada a consulta a trabalhos acadêmicos, razão pela qual é importante destacar que foram encontradas, embora em número reduzido, conforme se observa na lista de referências deste estudo, produções de análise semelhantes à temática proposta, que vieram contribuir com o presente estudo e juntamente com ele promover o aprofundamento do tema aqui pesquisado.

\section{Considerações finais}

O controle dos atos de gestão pública se efetiva por intermédio de um sistema que tem por finalidade assegurar as boas práticas de gestão pública, evitando danos ao erário e má gestão dos agentes públicos, caracterizando, assim, uma atividade inerente a qualquer tipo de instituição ou organização, compreendendo aspectos administrativos e financeiros.

Por meio da efetividade das técnicas de controle, garante-se o cumprimento das normas e que sejam atingidas as metas previstas pelo ente público, de forma a possibilitar o desenvolvimento e a execução eficientes de políticas públicas e um retorno à população, de 
forma a aproximar-se da accountability, pois, como argumenta Campos (1990, p. 47), accountability é uma tentativa de reduzir o hiato existente entre a efetividade das ações governamentais e as necessidades dos cidadãos.

Para executar essa tarefa, o sistema normativo brasileiro previu a existência do controle externo que "é o dever-poder atribuído constitucionalmente e instituído por lei como competência específica de certos poderes e órgãos" (JUSTEN FILHO, 2011, p. 1111), sendo ele exercido pelo Poder Legislativo com auxílio dos Tribunais de Contas, pelo Poder Judiciário e pela Sociedade, cada um com suas atribuições específicas.

O Tribunal de Contas do Estado do Paraná, dentre as suas atribuições, possui a atribuição legal e normativa de apreciar as contas dos chefes do executivo municipal emitindo parecer prévio.

Analisando as normativas da Corte de Contas do Estado do Paraná, verifica-se que, ao analisar essas contas anuais, a expressão "prestação de contas" poderia estar mais próxima ao conceito de accountability não fosse a delimitação feita pelo TCE/PR, por meio de Instruções Normativas, que delimitam o escopo e atribuições da Corte de Contas, restringindo sua análise aos aspectos mais formais do controle, deixando, a cargo do órgão de controle interno municipal, a atribuição exclusiva de avaliação da efetividade das políticas, plano e programas de governo, como da execução e atingimento das metas do PPA.

Cabe observar com maior atenção o Art. 216 do Regimento Interno, que prevê expressamente o controle da operacionalidade da gestão pública pela Corte de Contas Estadual, bastando apenas uma vontade maior do TCE/PR de viabilizar essa ampliação de escopo de análise com uma simples regulamentação do próprio dispositivo legal, com maior detalhamento.

Afinal, por meio da avaliação da efetividade, eficácia e eficiência dos programas e políticas governamentais é que se pode apreciar e quantificar o retorno dado à comunidade local, expressão do sistema representativo de governo, bem como munir essa sociedade de dados concretos e efetivos para formar um juízo de valor mais elaborado sobre a atuação de seus representantes.

Essa delimitação de escopo também deixa de promover uma discussão mais abrangente e transparente da gestão pública, uma vez que impede a produção e a divulgação de elementos que explicam as ações e atitudes tomadas pelos gestores, o que permitiria um nível mais elevado de transparência e a obtenção de elementos mais concretos pelo Legislativo Municipal que julgará as contas.

Assim, dos estudos referenciados nas esferas exploratória, bibliográfica, documental e de observação teórico-empírica, denota-se que a Corte de Contas do Paraná, ao analisar a prestação de contas do governo municipal relativas ao exercício de 2012 , não exerce todo o seu potencial de accountability, deixando de adentrar no aspecto substancial de atingir metas e executar políticas públicas e programas de governo, tarefa importantíssima para fins de dar à população dados efetivos e concretos sobre a gestão municipal e o desenvolvimento local, não apenas em seu aspecto econômico, mas também no social e ambiental.

\section{REFERÊNCIAS}

ALA-HARJA, Marjukka; HELGASON, Sigurdur. Em direção às melhores práticas de avaliação. Revista do Serviço Público, Brasília, v. 51, n. 4, p. 5-59, out./dez. 2000.

ARANTES, Rogério Bastos; ABRUCIO, Fernando Luiz; TEIXEIRA, Marco Antonio Carvalho. A imagem dos tribunais de contas subnacionais. Revista do Serviço Público, v. 56, n. 1, p. 57-83, 2005. 
BOVENS, Mark. Analysing and assessing public accountability. A conceptual framework. European Governance Papers (Eurogov), n. C-06-01, jan. 2006. Disponível em: <http://www.uu.nl/SiteCollectionDocuments/REBO/REBO_USBO/REBO_USBO_OZZ/Anal ysing\%20and\%20Assessing\%20Public\%20Accountability1.pdf $>$. Acesso em: 10 jan. 2014.

BRASIL. Lei Ordinária n. 4.320, de 17 de março de 1964. Estatui Normas Gerais de Direito Financeiro para elaboração e controle dos orçamentos e balanços da União, dos Estados, dos Municípios e do Distrito Federal. Diário Oficial da União (DOU), Brasília, DF, 23 mar. 1964. Disponível em: <http://www.planalto.gov.br/ccivil_03/leis/14320.htm>. Acesso em: 10 jan. 2014.

Constituição da República Federativa do Brasil (1988). Disponível em: $\overline{<\mathrm{http} / / /}$ www.planalto.gov.br/ccivil_03/constituicao/Constituicao.htm>. Acesso em: 20 fev. 2014.

Lei Complementar $\mathrm{n}^{\mathrm{o}} 101$, de 4 de maio de 2000. Estabelece normas de finanças públicas voltadas para a responsabilidade na gestão fiscal e dá outras providências. Diário Oficial da República Federativa do Brasil, Brasília, DF, 5 maio 2000. Disponível em: $<$ http://www.planalto.gov.br/ccivil_03/leis/lcp/lcp101.htm>. Acesso em: 24 fev. 2014.

CALIXTO, Giniglei Eudes; VELÁSQUEZ, Maria Dolores Pohmann. Sistema de Controle Interno na Administração Pública Federal. Revista Eletrônica de Contabilidade. Jul./2005. Disponível em: <http://www.ufpi.br/subsiteFiles/parnaiba/arquivos/files/rd-ed1ano1artigo6_antoniofilho.PDF>. Acesso em: 22 jan. 2014.

CAMPOS, Anna Maria. Accountability: quando poderemos traduzi-la para o português? Revista de Administração Pública, Rio de Janeiro, v. 24, n. 2, p. 30-50, 1990.

CASTRO, José Nilo de. Julgamento das contas municipais. 3. ed., rev., atual., ampl. Belo Horizonte: Del Rey, 2003.

CHAVES, Francisco Eduardo Carrilho. Controle externo na gestão pública. 2. ed. Niterói: Impetus, 2009.

DENHARDT, Janet V.; DENHARDT, Robert B. The new public servic: serving, not steering. Expanded edition. Nova York: M. E. Sharp, 2007.

DI PIETRO, Maria Sylvia Zanella. Direito Administrativo. 24. ed. São Paulo: Atlas, 2011.

GARCIA, Emerson; ALVES, Rogério P. Improbidade Administrativa. Rio de Janeiro: Lumen Júris, 2002.

GIACOMONI, James. Orçamento Público. 15. ed. São Paulo: Atlas, 2010.

GUERRA, Evandro Martins. Os controles externo e interno da Administração Pública. 2. ed. rev. e ampl. Belo Horizonte: Fórum, 2005.

JUSTEN FILHO, Marçal. Curso de Direito Administrativo. 2. ed. São Paulo: Saraiva, 2006.

Curso de Direito Administrativo. 8. ed. São Paulo: Saraiva, 2011.

LINS, Cristiane de Meira. Divergências entre o parecer prévio do Tribunal de Contas do Estado (TCE) e o resultado do julgamento das contas anuais de Prefeitos em 
Pernambuco. 2012. 134 f. Dissertação (Mestrado em Administração Pública) - Fundação Getulio Vargas, Escola Brasileira de Administração Pública e de Empresas, Rio de Janeiro, 2012.

MATIAS-PEREIRA, José. Governança no setor público. São Paulo: Atlas, 2010.

OLIVEIRA, A. G.; CARVALHO, H. A.; CORRÊA, D. P. Governança pública e governabilidade: accountability e disclosure possibilitadas pela contabilidade aplicada ao setor público como instrumento de sustentabilidade do Estado. Revista de Educação e Pesquisa em Contabilidade, Brasília, v. 7, n. 1, p. 91-104, jan./mar. 2013.

PARANÁ. Tribunal de Contas do Estado. Lei Complementar 113, de 15 de dezembro de 2005. Dispõe sobre a Lei Orgânica do Tribunal de Contas do Estado do Paraná. Diário Oficial $\mathrm{n}^{\mathrm{o}}$. 7123,15 dez. 2005. Disponível em: $<\mathrm{http}$ ://www.legislacao.pr.gov.br/legislacao/pesquisarAto.do?action=exibir\&codAto=7482\&i ndice $=1 \&$ totalRegistros=3>. Acesso em: 5 jan. 2014 .

. Tribunal de Contas do Estado. Resolução 01, de 24 de janeiro de 2006. Regimento Interno do Tribunal de Contas do Estado do Paraná. Disponível em: $<$ http://www1.tce.pr.gov.br/multimidia/2013/8/pdf/00248460.pdf $>$. Acesso em: 10 jan. 2014.

Tribunal de Contas do Estado. Instrução Normativa 65/2011. Dispõe sobre as prestações de contas anuais das administrações direta e indireta municipais, nos termos dos artigos 216 e 226 e seus parágrafos, do Regimento Interno, e dá outras providências. Atos Oficiais do Tribunal de Contas do Estado do Paraná, Curitiba, PR, n. 332, 13 jan. 2012, p. 114-119. Disponível em: <http://www1.tce.pr.gov.br/multimidia/2012/1/pdf/00240325.pdf>. Acesso em: 12 jan. 2014.

. Tribunal de Contas do Estado. Instrução Normativa 90/2013. Estabelece o escopo e os reflexos para aplicação na análise da prestação de contas municipal relativa ao exercício de 2012, compreendendo os Poderes Executivo e Legislativo Municipal, a administração direta e indireta, e dá outras providências. Diário Eletrônico do Tribunal de Contas do Estado do Paraná, Curitiba, PR, n. 603, 21 mar. 2013, p. 91-92. Disponível em: $<$ http://www1.tce.pr.gov.br/multimidia/2013/3/pdf/00243088.pdf $>$. Acesso em: 10 jan. 2014.

PINHO, José Antônio Gomes de; SACRAMENTO, Ana Rita Silva. Accountability: já podemos traduzi-la para o português? Revista de Administração Pública, Rio de Janeiro, v. 43, n. 6, p. 1343-1368, nov./dez. 2009.

ROCHA, Arlindo Carvalho. A realização da accountability em pareceres prévios do Tribunal de Contas de Santa Catarina. Revista de Administração Pública, Rio de Janeiro, v. 47, n. 4, p. 901-926, jul./ago. 2013.

SILVA, Christian Luiz da; BASSI, Nadia Solange Schmidt. Políticas Públicas e Desenvolvimento Local. In: SILVA, Christian Luiz da (Org.). Políticas públicas e desenvolvimento local: instrumentos e proposições de análise para o Brasil. Petrópolis, RJ: Vozes, 2012.

SOUZA, Marcelo Lopes de. Mudar a cidade: uma introdução crítica ao planejamento e à gestão urbanos. Rio de Janeiro: Bertrand Brasil, 2002. 
TREVISAN, Andrei Pittol; VAN BELLEN, Hans Michael. Avaliação de políticas públicas: uma revisão teórica de um campo em construção. Revista de Administração Pública, Rio de Janeiro, v. 42, n. 3, p. 529-50, 2008.

VERGARA, Sylvia Constant. Projetos e relatórios de pesquisa em Administração. São Paulo: Atlas, 2004. 